\title{
Machinability of Stellite 6 hardfacing
}

\author{
M. Benghersallah ${ }^{1}$, L. Boulanouar ${ }^{1}$, G. Le $\mathrm{Coz}^{2}$, A. Devillez ${ }^{2}$, D. Dudzinski ${ }^{2}$ \\ ${ }^{I}$ Mechanical laboratory of Materials and Plant Maintenance (LR3MI), Mechanical Department of \\ Engineering, University Badji Mokhtar BP12, Annaba 23000.E-mail: bengher moh@yahoo.fr \\ ${ }^{2}$ Laboratoire de Physique et Mécanique des Matériaux UMR CNRS 7554 \\ ISCMP - Bâtiment C Ile du Saulcy57045 METZ Cedex 01 France
}

\begin{abstract}
This paper reports some experimental findings concerning the machinability at high cutting speed of nickel-base weld-deposited hardfacings for the manufacture of hot tooling. The forging work involves extreme impacts, forces, stresses and temperatures. Thus, mould dies must be extremely resistant. The aim of the project is to create a rapid prototyping process answering to forging conditions integrating a Stellite 6 hardfacing deposed PTA process. This study talks about the dry machining of the hardfacing, using a two tips machining tool and a high speed milling machine equipped by a power consumption recorder Wattpilote. The aim is to show the machinability of the hardfacing, measuring the power and the tip wear by optical microscope and white light interferometer, using different strategies and cutting conditions.
\end{abstract}

Key words: Weld hardfacing/ base-cobalt/ Machinability/ High speed milling/ Wattpilote

\section{Introduction}

Prototyping is the realisation of models, before the industrial manufacturing start of a new mechanical part, to test different aspects and particularly it feasibility, it functionality and more generally, it design. In the context of the world competition, the necessity to develop a new product and to manufacture it in a minimum of time has driven firms to the expansion of rapid prototyping and rapid tooling concept $[1,2]$. Proposing to answer to this problematic, the ANR PROMETFOR project studies a rapid tooling process, realised by metallic projection with a Plasma Transferred Arc system (PTA), to realize forging die mould [3]. This study is a part of this project. .Metallic projection process on fritted or polymerised substrate could permit to obtain a die mould with a near net shape. Finishing of such die would be done by High Speed Machining (HSM) milling centre, able to realize complex shapes. The deposed material being hard to machining with dry condition, optimisation of the cutting parameters and judicious tools choice are an important aim of the project. This project proposes an innovated alternative to actual processes, conduces to the use of new hard refractory materials giving to the die higher wear resistance and higher mechanical and thermal properties, resisting to the forging extreme conditions.

To increase die moulds life, hardfacing is currently used. Cobalt-base and nickel-base superalloy deposed by welding are used for their remarkable wear and oxidizing resistance on high temperature conditions. Hardfacing is also used on preventive or curative terms to increase die life on service [4]. Nickel and cobalt-base have begun inescapable and particularly Stellite 6 hardfacing. Stellite 6 is a powder of cobalt-base alloy hardfacing designed to produce hard and thick coating [5]. Stellite 6 coating is recommended for it high resistance to abrasive wears and for the contact with hard surfaces. Deposition techniques have progressed and, today, processes used are TIG process (Tungsten Inert Gas), MIG process (Metal Inert Gas) and PTA process (Plasma Transferred Arc) [3]. The last one has been choice for this study.

This is an Open Access article distributed under the terms of the Creative Commons Attribution-Noncommercial License 3.0, which permits unrestricted use, distribution, and reproduction in any noncommercial medium, provided the original work is properly cited. 


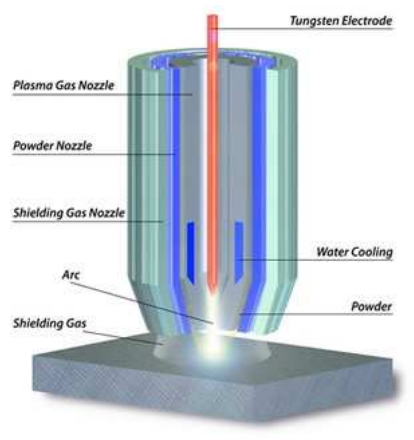

Fig 1. Schematic diagram of PTA process. [3]

PTA process is a mix of the techniques of blowed plasma projection and welding hardfacing (MIG / TIG). PTA permits plates with excellent metallurgic quality. The filler material is injected in the shape of powder in the PTA torch equipment and melted by the heat source of the electric arc. High speed fusion and dilution allow to obtain extremely thin and heavy structure.

Geometrical precision and surface roughness of functional shapes are subjected to very strict tolerances. Hardfacing layers machining is unavoidable, that why the best work conditions must be found to guaranty the profitability of this new technique. However, superalloy machinability in dry conditions is famed difficult. But, thanks to tools development, machining of strongly alloyed with a $60 \mathrm{HRC}$ hardness is possible. Progress of machine tool design is also a factor of development of strong materials machining. The last evolution is certainly the high speed machining introduction (HSM)

HSM for Stellite hardfacing layers is just at its first steps. In fact, conclusion of studies about high speed and dry machining of hardfacing [6-8] show that machining are limited by a premature wear. Machining is escorted by a chip adhesion, a cutting edge chipping, a grinding and a strain hardening of the machined layer. Different studies about machining performance of new cutting materials showed some incentives results for cutting tool manufacturer [9-14] and give bases about cutting conditions for high performance materials milling and turning [15-18]. HSM is characterised by cutting speeds much higher than for conventional machining and by low cutting thickness. It involves specifically cutting phenomenon as high cutting temperatures, exhausted by the chip, or special kind of tool wear (grinding, diffusion). It also characterised by high mechanical stresses and deformation at the tool/part interface which involves research and development for machine and tool manufacturer. Thus, tools used for such process are principally carbides, ceramics, cubic boron nitrides (CBN) or polycrystalline diamonds (PCD). A fine grain substrate will be wear resistant but brittle. A middle grain will be impact resistant but sensible to wear. Tool coatings, mono or multilayer, deposed by CVD or PVD process on the carbide substrate, can improve the tip giving particular properties function of the material machined. Among the coating used, some can be quoted. TiN coating is the older, it is versatile and can be a good initial choice when it is difficult to determinate the most appropriate coating. TiCN is an advanced coating with special properties. It has a high impact resistance, has the lowest friction coefficient of the PVD coatings but is limited by high temperature $\left(400^{\circ}\right)$. However, it adheres particularly to the substrate, so it used as first layer. $\mathrm{Al}_{2} \mathrm{O}_{3}$ coating is good choice when chemical stability and cratering wear resistance is researched but must be deposed by CVD, which affects the substrate. TiAlN is actually the high performance multilayer coating used for HSM. It presents a hardness of $90 \mathrm{HRC}$ and an oxidation temperature of $815^{\circ} \mathrm{C}$ [99]. It is possible to depose multilayer coatings to obtain the appropriate characteristics to the machining. Finally, manufacturers create their own "recipe" as Saturn coating, TiAlN with secret proportions.

\section{Presentation of the experimental works}

\subsection{Materials used}

Test parts are two steel slugs 55NCDV7 coated by a Stellite 6 monolayer and bilayer hardfacing deposed by a PTA process. Its present some irregularities on it superior part. Hardfacing forms grooves as shown on figure 2 . Hardfacing also presents rare imperfections as holes and chinks but it can't be compared to imperfections of a MIG hardfacing process. 
Tests realised by the CRITT (Regional Technology Training Centre) of Charleville Mézière show the hardness repartition function of the depth. Result is presented on figure 3. For the monolayer PTA hardfacing, the hardness on the skin is near of $750 \mathrm{HV} 0.2$ but falls at $500 \mathrm{HV} 0.2$ at $3 \mathrm{~mm}$ depth. For the MIG hardfacing, the hardness is only $400 \mathrm{HV} 0.2$ but doesn't depend of depth. Hardness repartition corresponds to phenomenon observed by C. K. Sha and al. [19] after laser deposition of $\mathrm{NiAl}+\mathrm{ZrO}_{2}$ on $\mathrm{Ti}-6 \mathrm{Al}-4 \mathrm{~V}$.

\subsection{High Speed Milling machine.}

Machining tests have made on the HSM centre Röders RP600 of the LPMM, see figure 6. The milling centre is instrumented by Wattpilotes which allow to record the power consumption of the spindle, $\mathrm{x}, \mathrm{y}$ and $\mathrm{z}$ axis motors. Milling centre 3 axis, Power $17 \mathrm{Kw}$, Revolution speed Max $36000 \mathrm{rev} / \mathrm{min}$, Feed speed $\max 60 \mathrm{~m} / \mathrm{min}$, HSK E50 30 tools, Diametre $\max 20 \mathrm{~mm}$, Feed $\max X=600 \mathrm{~mm}, Y=540 \mathrm{~mm}, Z=300 \mathrm{~mm}$, Numerical processor RMS6, programmation ISO

\subsection{Milling technique}

Literature and experiment of precedent studies advise to use a down milling technique for hard materials. One cutting represents a milling of $100 \mathrm{~mm}$ along $\mathrm{Y}$ axis. $\mathrm{X}$ and $\mathrm{Z}$ axes stay fix. Between two cuttings, the offset is the distance $a_{e}$. Cutting depth $a_{p}$ is defined to machine only the hardfacing. Substrate stays intact.

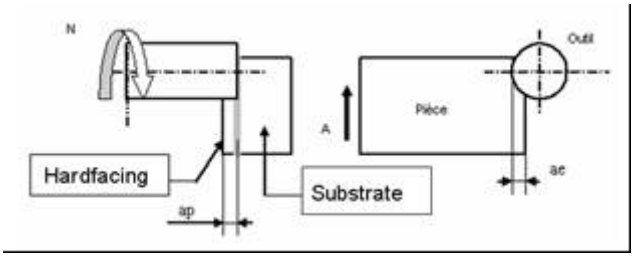

Fig 2. Schematic diagram of machining principle.

Series of test on hardfacing allows testing five kinds of tips:

- 3040, 1030, 4240 and 4030 developed and commercialised by Sandvik Coromant.

-H13A + Saturn coating developed by the firm Metaplas Ionon.

A first cutting speed is used to compare the tips comportment on the monolayer hardfacing, comparing wear and power consumption. The best tips are qualified for a second cutting test on the bilayer hardfacing, to determinate the appropriate cutting speeds.

\subsection{Cutting tools and tips}

Cutting tool is a cylindrical mill with two carbide tips referenced Sandvik Coromant R390. Five coating compositions are tested.

\subsection{Power consumption measurement principle}

In this operation, the usual cutting force acquisition is replaced by the recording of the power consumed by the motors by means of power controller "WATTPILOTE". These power controllers are developed by the society DIGITAL WAY, who is an industrial partner of the research team "High Speed Machining" of our laboratory.

\subsection{Optical microscope}

The optical microscope TESA and it software TESA VISIO is used to observe the tool wear evolution along the cutting tests. It permits to determinate the tool life. The qualification criterion is the degradation of the tetragonal insertions. Classically, in industry, it is considered that acuity tool is degraded after a clearance wear of $0.3 \mathrm{~mm}$ [24]. This criterion is used to determinate the test end.

\subsection{White light interferometer}

A Veeco NT1100 (Wyko®) Optical Profiler, using the white light interferometry technique presented by Devillez et al [25] is employed to monitor cutting parameters and to generate 3D images of the wear patterns of the cutting tools. This technique was also used with the same objectives by Dawson and Kurfess [26]. 


\section{Results and discussion.}

\subsection{Power signal exploitation.}

All Wattpilotes have been activated during test. Electrical power consumed by $\mathrm{x}, \mathrm{y}, \mathrm{z}$ and spindle axes engines have been recorded and treated. Calibration of Röders power transducer is not finished, so power can't be conversed into force. So, work is based on power signal.

Spindle power signal is extremely interfered for lower cutting speed. When the power increases, the noise disappears.

\subsection{Study of monolayer hardfacing machinability.}

The first machining test of monolayer PTA permits to classify five different tips to qualify the bests. Cutting conditions used are:

Cutting speed $\mathrm{Vc}=190 \mathrm{~m} / \mathrm{min}$,

Feed per tooth $\mathrm{f}_{\mathrm{z}}=0.067 \mathrm{~mm} / \mathrm{th}$

Radial cutting depth $\mathrm{a}_{\mathrm{e}}=0.3 \mathrm{~mm}$,

Cutting depth $\mathrm{a}_{\mathrm{p}}=3 \mathrm{~mm}$.

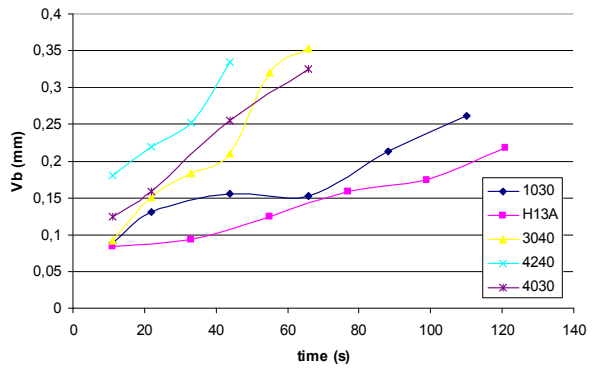

Fig 3. Power consumption for $\mathrm{Vc}=190 \mathrm{~m} / \mathrm{min}$ monolayer hardfacing.

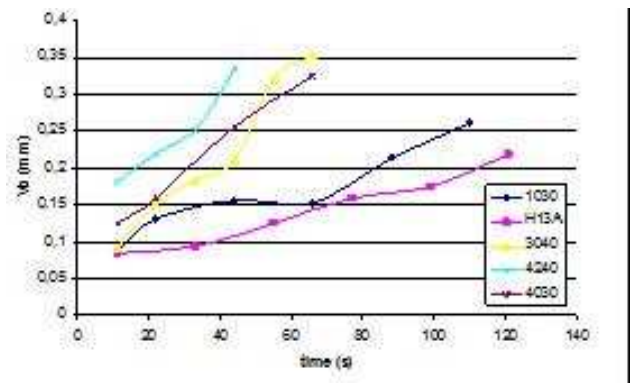

Fig. 4. Wear evolution $\mathrm{Vb}$ for $\mathrm{Vc}=190 \mathrm{~m} / \mathrm{min}$ monolayer hardfacing.

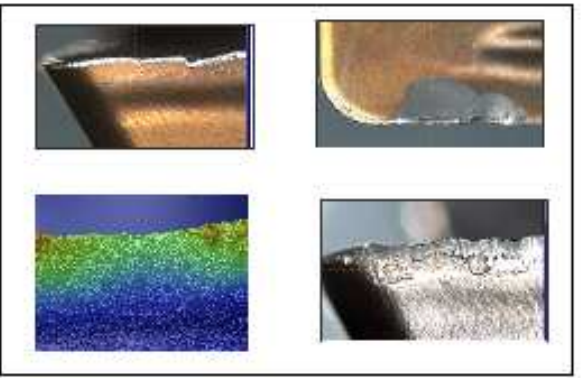

Fig. 5. Different types of wear obtained by (a), (b), (d) optical microscope and (c) interferometric microscope.

\subsection{Study of bilayer hardfacing machinability with $V c=190 \mathrm{~m} / \mathrm{min}$.}

Cutting conditions are: 
Cutting speed $V c=190 \mathrm{~m} / \mathrm{min}$, Feed per tooth $\mathrm{f}_{\mathrm{z}}=0.067 \mathrm{~mm} / \mathrm{th}$, Radial cutting depth $\mathrm{a}_{\mathrm{e}}=0.3 \mathrm{~mm}$, Cutting depth $\mathrm{a}_{\mathrm{p}}=5 \mathrm{~mm}$

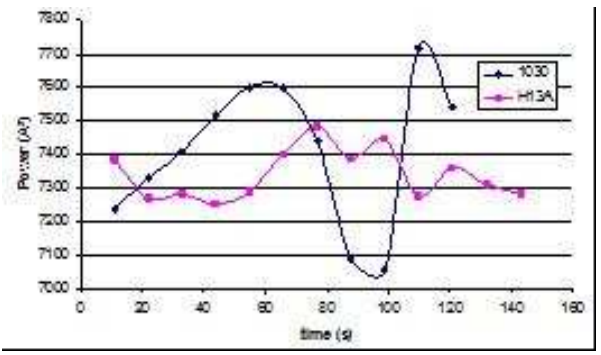

Fig.6. Power consumption for $\mathrm{Vc}=190 \mathrm{~m} / \mathrm{min}$ bilayer hardfacing.

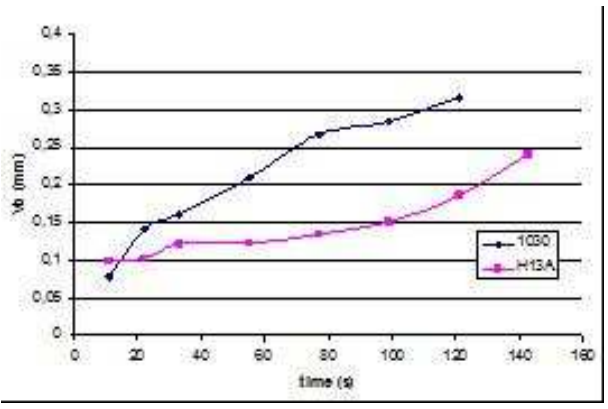

Fig.7. Wear evolution $\mathrm{Vb}$ for $\mathrm{Vc}=190 \mathrm{~m} / \mathrm{min}$ bilayer hardfacing.

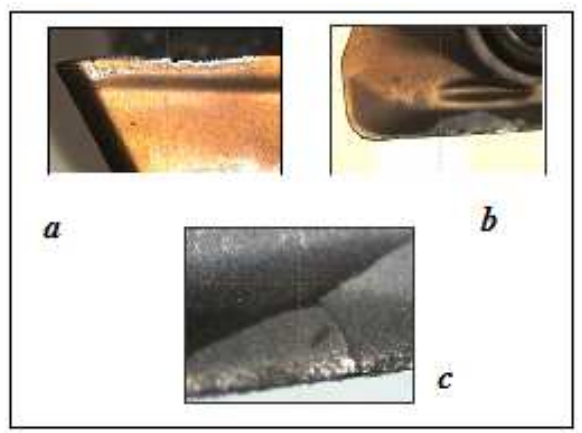

Fig.8. Types of wear for (a)(b) 1030 tip and (c) H13A Saturn tip.

\subsection{Study of bilayer hardfacing machinability with $\mathrm{Vc}=120 \mathrm{~m} / \mathrm{min}$.}

Cutting conditions are: Cutting speed $\mathrm{Vc}=120 \mathrm{~m} / \mathrm{min}$, Feed per tooth $\mathrm{f}_{\mathrm{z}}=0.067 \mathrm{~mm} / \mathrm{th}$, Radial cutting depth $\mathrm{a}_{\mathrm{e}}=0.3 \mathrm{~mm}$, Cutting depth $\mathrm{a}_{\mathrm{p}}=5 \mathrm{~mm}$

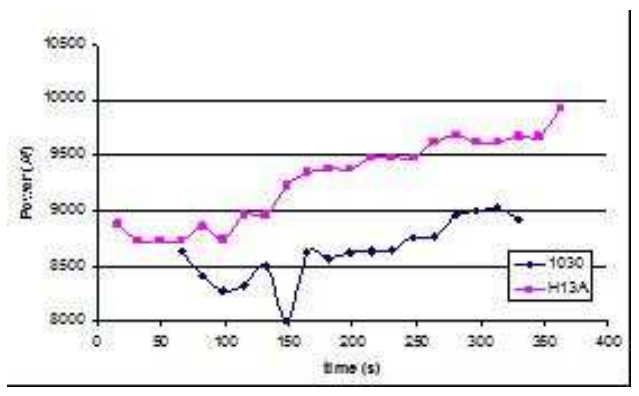

Fig.9. Power consumption for $\mathrm{Vc}=120 \mathrm{~m} / \mathrm{min}$ bilayer hardfacing. 


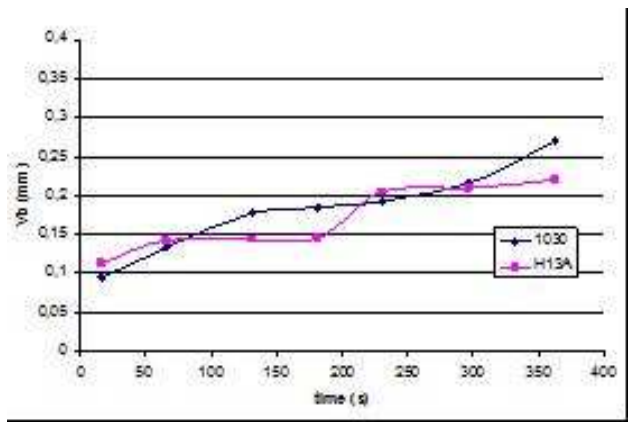

Fig.10.wear evolution $\mathrm{Vb}$ for $\mathrm{Vc}=120 \mathrm{~m} / \mathrm{min}$ bilayer hardfacing.

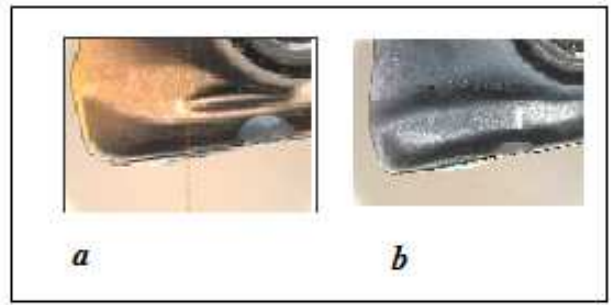

Fig.11. Chipping on the cutting faces (a) 1030 and (b) H13A + Saturn.

Analysis of power curves on figure3, shows that from the 5 tips qualities tested, 1030 and H13A + Saturn consume less power than other ones. Analysis of wear curves on figure4, shows that flank wear is fast for 4240 , 3040 and 4030, exceeding the admissible wear. Contrary to, 1030 and H13A + Saturn, $\mathrm{Vb}$ is less than $0.3 \mathrm{~mm}$. The tips observation by optical and interferometric microscope shows that for every tips, the flank wear increases continuously with a notch effect, followed by major chipping on the cutting face. The cutting edge looses it acuity. Little by little, the coating is pulled out and wear occurs in the substrate. This phenomenon is particularly at the tip area in contact with the top part of the hardfacing, at $3 \mathrm{~mm}$ of the nose, see figures $5 . \mathrm{a}$ and 5.b. Interferometric analysis of the cutting face and the flank face for the different tips shows that after the coating dismissed (thick layer of 6 to $7 \mu \mathrm{m}$ ), the flank wear is not so important in depth and notch is localised at $3 \mathrm{~mm}$ of the nose, and there is no crater on the cutting face, only chipping, see figure 5.c. It means by a great cohesion of the micrograins carbide substrate. Exception is made for the 3040 tip, figure5.d, which presents a major degradation all along it cutting edge.

Comparing power consumed and wear, only tips H13A + Saturn and 1030 are kept to the next of the study, and to resume

For grade 1030, flank wear is slow down and cutting face chipping is important.

For grade H13A + Saturn, flank wear is slow down too and seems to be braked. The cutting edge keeps it acuity but a large chipping is on the cutting face, driving to the test end.

1030 and H13A + Saturn have given some satisfaction results, comparatively to milling tests on the monolayer hardfacing, especially for tip H13A + Saturn. Analysis of power curves on figure 6 shows that power for 1030 is really unstable. Contrary to, H13A + Saturn power variation is quite stable and decreases at the test end. Power consumption of 1030 is globally higher than H13A + Saturn. Analysis of wear curves on figure 7 shows that the flank wears evolution is regular for the two tips and H13A + Saturn wear is slower. This wear resistance is due to the protection of the AlTiN nanocrystalline coating. However, when the coating is pulled out by the chafing and the chip adhesion, the middle grains substrate presents a remarkable weakness compare to the micrograins substrate of the tip 1030. The cutting face chipping of the 1030 is well operated and there is a resistance to the chipping area propagation. Then, it is the flank wear, see figure 8a which causes the test stop, by a maximal wear superior of the limit. This wear is the highest at $5 \mathrm{~mm}$ of the nose and, as for the first test; this phenomenon is particularly presented on the tip part in contact with the top part of the hardfacing, see figure 8b. The tip H13A + Saturn shows a coating pulling out, see figure8c.

The second machining test has given satisfaction and equivalent results for the two tips. Analysis of power curves on figure9 shows that power consumption increases during the test. H13A + Saturn power decreases during the first cutting of the test. Now, 1030 has best performance in term of power consumption. Wear curves 
of figure 10 show that the two tips have a good comportment during the test. Tip 1030 wear is progressive. For tip H13A + Saturn, the wear is made by stages: the first one at 50 second and the second one at 240 second.

Examination with microscope, figure 11, shows that the two tips present chipping on the cutting faces, at $5 \mathrm{~mm}$ of the nose. It is important to notice that the cutting speed affects the ration chipping wear / flank wear. The less the cutting speed, the most the flank wear is, compare to the chipping wear.

\section{Conclusions and future prospect.}

The experimental study realised permits to conclude that:

- The machinability of the PTA hardfacing layers of Stellite 6 is possible but hard.

- The responsible of the major wear is the 1 millimetre superior layer of the hardfacing (700 HV0.2) which conduces to a notch and a cutting face chipping.

- The cutting tips for milling have different kinds of wears: a progressive wear of the flank face characterised by a notch of the part in contact with the hardfacing top part; and a severe chipping in the cutting face. During the high speed machining of hard metals characterised by a hard machinability, it is recommended to reduce the admissible flank wear criteria Vbmax to $[\mathrm{Vb}]=0.2 \mathrm{~mm}$. The chipping, by it length and it depth can be another criteria to considerate.

- The most appropriate cutting speed in term of cutting forces is $190 \mathrm{~m} / \mathrm{min}$

- The implementation of the Wattpilote system to the Röders RP600 for the machining control is efficient. It gives the opportunity to follow the evolution of the cutting process in term of power.

- Power curves of $\mathrm{X}, \mathrm{Y}$ and especially $\mathrm{Z}$ are in phase with the wear curves. The power improving during the milling process is probably linked to the tool wear. Theoretically, it is possible to follow and to control the tips wear with the power help.

The methodology adopted for the tests and the criteria considered to quantify the parameters integrated in the process give a qualification of the tool without incertitude. Thus, two tips have been awarded with the aim of industrial applications and the coating Saturn has proved it particular effectiveness for hard metal machining.

The future prospects can be resumed to:

To resolve the problem of the fast coating pull out of the cutting face, it is necessary to develop, on another study, the phenomenon of the chip adhesion and the coating properties.

A local lubrification on the cutting face by an air blow mixed with a freeze and lubricant properties liquid could improve the results.

In parallel of the study, the hardfacing by Stellite 21 with PTA process has been realized. It hardness is low, near of $500 \mathrm{HV} 0.2$. The die mould has shown better properties and doubles it bench life. Stellite 6 machining conclusions could be applied to this new hardfacing.

To complete the study of the Stellite 6 hardfacing, a measurement of the residual stress in the milling part is programmed.

To complete the study, other coatings must be tested.

\section{References}

1. S. Akula and K.P. Karunakaran. Hybrid adaptive layer manufacturing: An Intelligent art of direct metal rapid tooling process. Robotic and Computer Integrated Manufacturing, Volume 22, Issue 2 (2006), 113-123.

2. J.L. Song, Y.T. Li, Q.L. Deng and D.J. Hu. Rapid prototyping manufacturing of silica sand patterns based on selective laser ssintering. Journal of Materials Processing Technology Volumes 187-188, (2007), Pages 614-618

3. A. Gatto, E. Bassoli and M. Fornari. Plasma Transferred Arc deposition of powdered high performances alloys: process parameters optimisation as a function of alloy and geomet configuration.

Surface and CoatingsTechnology Volume 187, Issues 2-3, 22 October 2004, Pages 265-271

4. L. Fouilland, L. Iordache, M. El Mansori, A. Huguet. Caractérisation métallurgique des couches de rechargement base-Cobalt par soudage de matrice à chaud: influence des paramètres d'élaboration. Matériaux et techniques 93, 163-169 (2005).

5. T.S. Sidhu, S. Prakash and R.D. Agrawal. Studies of the metallurgical and mechanical properties of high velocity oxy-fuel sprayed stellite- 6 coatings on Ni- and Fe-based superalloys. Surface and Coatings Technology

Volume 201, Issues 1-2, 12 September 2006, Pages 273-281

6. M. EL Mansori, M. Nouari. Dry machinability of nickel-based weld-hardfacing layers for hot tooling. International Journal of Machine Tools \& Manufacture 47 (2007) 1715-1727. 
7. M. El Mansori, L. Fouilland-Paillé et F. Pierron. Usinabilité à grande vitesse et à sec des couches du rechargement base-nickel par soudage d'outillage à chaud. Mécanique \& Industries 6, 211-225 (2005).

8. X.J. Rena, Q.X. Yang, R.D. James, L. Wang. Cutting temperatures in hard turning chromium hardfacings with PCBN tooling. Journal of Materials Processing Technology 147 (2004) 38-44.

9. CETIM, Les atouts de l'usinage à grande vitesse: Fraisage et perçage des métaux durs, 1996.

10. E. Aslan. Experimental investigation of cutting tool performance in high speed cutting of hardened X210Cr12 cold-work tool steel (62HRC). Material and design May 2004.

11. M. Nordin, R. Sundstrom, T.I. Selinder, S. Hogmark. Wear and failure mechanisms of multilayered PVD TiN TaN coated tools when milling austenitic stainless steel Surface and coatings technology 133-134 (2000) 240-246.

12. M. Nordin, M.Larsson, S. Hogmark. Mechanical and tribological properties of multilayered PVD TiN/CrN,TiN/MoN, TiN/NbN, TiN/TaN coating on cemented carbide. Surface and coatings technology 106 (1998) 234-241.

13. N. Camuscu, E. Aslan A comparative study on cutting tool performance in end milling of AISI D3tool steel. Materials processing technology Avril 2005.

14. C.H. Che Haron a, , A. Ginting b, H. Arshad. Performance of alloyed uncoated and CVD-coated carbide tools in dry milling of titanium alloy Ti-6242S. Journal of Materials Processing Technology 185 (2007) 77-82.

15. A. Devillez, F. Schneider, S. Dominiak, D. Dudzinski, D. Larrouquere. Cutting forces and wear in dry machining of Inconel 718 with coated carbide tools. Wear 262 (2005) 931-942.

16. M. Arndt, T. Kacsich, Performance of new AlTiN coatings in dry and high speed cutting, Surf. Coat. Technol. 163/164 (2003) 674-680.

17. J.L. Endrino, G.S. Fox-Rabinovich, C. Gey, Hard AlTiN, AlCrN PVD coatings for machining of austenitic stainless steel, Surf. Coat. Technol. 200 (24) (2006) 6840-6845

18. J.A Ghani, I.A.Choudhury, H.Hassan. Application of taguchi method in the optimization of end milling parameters. Materials processing technology 145(2004) 84-92.

19. C.K. Shaa, J.C Lin b, H.L. Tsai. The impact characteristics of Ti-6Al-4V plates hardfacing bylaser alloying NiAl + ZrO2 powder. Journal of Materials Processing Technology 140 (2003) 197-202.

20. Catalogue "Sandvik Coromant". The new generation of milling grades. Six new ways to better productivity.

21. T. Y. KIM, J. WOO, D. SHIN, J. KIM, Indirect cutting force measurement in multi-axis simultaneous NC milling processes, International Journal of Machine Tools \& Manufacture 39 (1999) 1717-1731.

22. T.Y. KIM, J. KIM, Adaptive cutting force control for a machining center by using indirect cutting force measurement, Int. J. Mach. Tools Manufact. 36 (8) (1996) 925-937.

23. C. R. BALKRISHNA, Y. C. SHIN, A comprehensive dynamic cutting force model for chatter prediction in turning. International Journal of Machine Tools \& Manufacture, 39 (1999) 1631-1654. 